\title{
Development of a new glass-ceramic by means of controlled vitrification and crystallisation of inorganic wastes from urban incineration
}

\author{
M. Romero ${ }^{\mathrm{a}}$, R. D. Rawlings ${ }^{\mathrm{a}}$ and J. Ma. Rincón ${ }^{\mathrm{b}}$

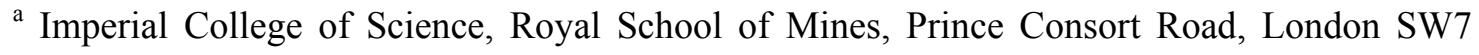 \\ 2BP, UK \\ ${ }^{\mathrm{b}}$ Instituto E. Torroja de Ciencias de la Construcción, Serrano Galvache s/n, 28033 Madrid, \\ Spain
}

\begin{abstract}
This paper reports the results of a study of the feasibility of recycling the solid residues from domiciliary waste incineration by producing a glass-ceramic. The major components of the raw material (TIRME F+L), which was from a Spanish domiciliary incinerator, were $\mathrm{CaO}, \mathrm{SiO}_{2}$ and $\mathrm{Al}_{2} \mathrm{O}_{3}$ but nucleating agents, such as $\mathrm{TiO}_{2}, \mathrm{P}_{2} \mathrm{O}_{5}$, and $\mathrm{Fe}_{2} \mathrm{O}_{3}$ were also present in reasonable amounts. It was found that a relatively stable glass with suitable viscosity could be obtained by mixing $65 \mathrm{wt} \%$ TIRME $\mathrm{F}+\mathrm{L}$ with $35 \mathrm{wt} \%$ glass cullet. The heat treatment required to crystallise the glass produced from this mixture, designated TIR65, was nucleation at $560^{\circ} \mathrm{C}$ for $35 \mathrm{~min}$ followed by crystal growth at $100^{\circ} \mathrm{C}$ for $120 \mathrm{~min}$. The resulting glass-ceramic contained a number of crystalline phases, the most stable being clinoenstatite $\left(\mathrm{MgSiO}_{3}\right)$, or perhaps a pyroxenic phase which incorporates $\mathrm{Ca}, \mathrm{Mg}$ and $\mathrm{Al}$ in its composition, and åkermanite $\left(\mathrm{Ca}_{2} \mathrm{MgSi}_{2} \mathrm{O}_{7}\right)$. The microstructure contained both fibre-like and dendritic crystals. The mechanical properties were acceptable for applications such as tiles for the building industry.
\end{abstract}

Keywords: incinerator waste products; microstructure-final; mechanical properties; glass; glass ceramics.

\section{Introduction}

A major problem in developed countries is the large quantity of domiciliary solid waste (DSW) that is generated and which has to be disposed. For example, in Spain each inhabitant is estimated to produce $1.036 \mathrm{~kg}^{-1}$ day of DSW and the total for that country is about $15 \times 10^{-6}$ tons year [1]. A number of methods are used for disposal of DSW including dumping in the sea and in land-fill sites $(63.74 \%)$, treatment to produce fertilizer $(13.99 \%)$ and incineration 
(4.67\%)[2]. Although dumping is currently the most common disposal method, it is now considered to be environmentally unacceptable and a better strategy is the recycling of DSW. However recycling, which involves selection and classification of the waste materials, is only suitable for $47 \%$ of DSW and hence recycling alone cannot solve the disposal problem. The complementary, and growing option in Europe, for the disposal of the non-recyclable fraction $(53 \%)$ is incineration with energy recovery.

Unfortunately incineration is not without its difficulties. The incineration of DSW leaves large amounts of solid residues, such as bottom ashes, fly ashes and slag, which are produced in the proportion of 20-25 (wt\%) of the DSW incinerated. A single large European plant may produce fly ashes at a rate of 10,000 tons year $^{-1}$. These residues may be toxic due to concentration of heavy metals as well as organic pollutants and consequently they are classified in several European countries as a hazardous waste. Most residues are buried in landfills, which is a costly and environmentally unsatisfactory procedure. The increasing tendency for waste incineration, together with the rising economic and environmental costs of land-fill disposal, make it essential to search for new options for recovery or recycling of the solid residues from waste incineration.

Glass-ceramic materials, prepared by controlled devitrification of glasses, are used for technological applications ranging from biomedical implants to radomes. Controlled devitrification is only possible for certain glass compositions and usually involves a two stage heat treatment, namely a nucleation stage and a crystallisation stage. In the nucleation stage small nuclei are formed within the parent glass. After formation of stable nuclei, crystallisation proceeds by growth of a new crystalline phase [3]. Knowledge of nucleation and crystallisation parameters is important in the preparation of glass-ceramics with desired microstructures and properties.

Recent papers have reported on the use of vitrification and crystallisation processes to recycle different wastes such as red muds from zinc hydrometallurgy [4], coal fly ash [5, 6], iron blastfurnace slags [7], and even filter dust from waste incinerators[8] but, to the authors' knowledge, no attempt has been made to determine the nucleation and crystallisation parameters of glasses produced from wastes from domiciliary incinerators.

This paper reports the results of a study to characterise the fly ash from a Spanish domiciliary incinerator and to assess the feasibility of producing a glass-ceramic from this fly ash. In particular, the temperature range over which nucleation occurs, the temperature where the nucleation rate is a maximum, and the crystallisation kinetics have been determined together with a preliminary assessment of properties. 


\section{Materials and Methods}

\subsection{Raw material}

A mixture of the residue from a gas purification reactor, which is formed from an excess of $\mathrm{Ca}(\mathrm{OH})_{2}$ and calcium salts in purification of the acid gases, and fly ash from an incinerator in Mallorca (Spain) was supplied by Tirme, S.A. The mixture, designated TIRME F+L, was a grey colour and appeared to be homogeneous.

The mixture was characterised by means of particle size analysis (Malvern Laser Sizer with water as the transport medium), chemical analysis using an inductively coupled plasma method, phase constitution by $\mathrm{X}$-ray diffraction $\left(\mathrm{CuK}_{\alpha}\right.$ radiation in a Philips $\mathrm{PW} 1710$ diffractometer) and thermal stability by differential thermal analysis (Stanton Redcroft thermal analyser, STA-780 Series, using Pt crucibles with calcined alumina as reference in flowing air at $65 \mathrm{~cm}^{3} \min ^{-1}$ and a heating rate of $25^{\circ} \mathrm{C} \mathrm{min}^{-1}$ ).

\subsection{Crystallisation}

The first stage in glass-ceramic production is to produce a melt of suitable viscosity at a reasonable temperature $\left(\leq 1500^{\circ} \mathrm{C}\right)$ from which a glass may be formed. The glass forming tendencies of TIRME F+L, with and without additions of ground Spanish waste glass, was investigated by holding the various mixtures at $1500^{\circ} \mathrm{C}$, observing the pouring characteristics and monitoring the final product by X-ray diffraction (XRD).

Glass was prepared from a suitable glass forming TIRME F+L-waste glass mixture by melting in a platinum crucible at $1500^{\circ} \mathrm{C}$ for $30 \mathrm{~min}$. Usually the melt $(\sim 50 \mathrm{~g})$ was poured onto a preheated metal plate to produce a glass, annealed at $600^{\circ} \mathrm{C}$ for $2 \mathrm{~h}$ and slowly cooled to room temperature. In a few cases, in order to study the effect of cooling rate on crystallisation, a small amount of melt ( $\sim 5 \mathrm{~g}$ ) was quenched by pouring into water.

To ascertain whether there were differences in the crystallisation behaviour of annealed and quenched glasses, differential thermal analysis (DTA) measurements were performed on both bulk and powder $(<100$ and $300-500 \mu \mathrm{m})$ samples. The DTA tests were carried out as previously described for the study of TIRME F+L. The DTA curves were normalised with respect to the sample weight, which was in the range $12-15 \mathrm{mg}$. DTA was also used to determine the optimum nucleation temperature and time from measurements on 300-500 $\mu \mathrm{m}$ size particles ground and screened from the annealed glass. For the determination of the nucleation temperature, the glass particles were heated in the DTA apparatus at $15 \mathrm{~K} \mathrm{~min}^{-1}$ to different nucleation temperatures in the range 400 to $730^{\circ} \mathrm{C}$ inclusive, and held at the 
nucleation temperature for $30 \mathrm{~min}$. After the nucleation treatments the samples were heated, without removal from the DTA apparatus, at $15 \mathrm{~K} \mathrm{~min}^{-1}$ until crystallisation was complete, i.e. the temperature exceeded the finish temperature of the exothermic crystallisation peak. The plot of the height of the exothermic crystallisation peak, $\delta T_{p}$, versus the nucleation temperature allowed the specification of the optimum nucleation temperature from the maximum of the curve.

To determine the optimum nucleation time, DTA was performed using the same conditions as those for nucleation temperature determination except that the glass powder was held at the specified optimum nucleation temperature for different nucleation times (10-90 min inclusive) and then heated until crystallisation was completed. Typically a plot of $\delta T_{p}$ versus nucleation time reaches a plateau, the onset of which corresponds to the optimum nucleation time.

The value for the activation energy for crystallisation, $E$, was calculated from DTA data. $E$ was calculated from the heating rate dependence of the temperature, $T_{p}$, corresponding to the maximum of the exothermic peak. The glass powder was heated at $15 \mathrm{~K} \mathrm{~min}^{-1}$ until the optimum nucleation temperature and held at that temperature for the optimum nucleation time. The nucleated samples were then crystallised at seven heating rates, $\varphi$, namely $5,10,15,20$, 25, 30, $40 \mathrm{~K} \mathrm{~min}^{-1}$, and the data analysed using the equation proposed by Kissinger [9]:

$$
\ln \frac{\phi}{\mathrm{T}_{\mathrm{p}}^{2}}=-\frac{\mathrm{E}}{\mathrm{RT}_{\mathrm{p}}}+\mathrm{cte}
$$

where cte is a constant and $R$ is the gas constant.

The Avrami exponent, $n$, in the Johnson-Mehl-Avrami equation were also calculated. The Johnson-Mehl-Avrami model was developed to describe nucleation-growth processes in isothermal conditions:

$$
V_{f}=1-\exp \left(-g I U^{n} T^{n+1}\right)
$$

$V_{f}$ is the volume fraction, $g$ is a shape factor, $U$ is the growth rate, $I$ is the nucleation rate and $n$ is the Avrami parameter, which is related to the directionality of crystal growth and the time dependence of nucleation. The parameter $n$ was determined from the dimensions of the crystallisation exotherm using the equation: 


$$
\mathrm{n}=\frac{2.5}{\Delta \mathrm{T}} \mathrm{x} \frac{\mathrm{RT}_{\mathrm{p}}^{2}}{\mathrm{E}}
$$

where $\Delta T$ is the width of the exotherm at half maximum.

The optimum crystallisation temperature and time were estimated from X-ray diffraction (XRD) data from specimens $\left(10 \times 5 \times 5 \mathrm{~mm}^{3}\right)$ of the annealed glass that were given different heat treatments. After heat treatment the samples were ground and sieved to a particle size $<70 \mu \mathrm{m}$ and XRD data obtained using $\mathrm{CuK}_{\alpha}$ radiation. A plot of the ratio of the intensity of the maximum XRD intensity peak to the total peak intensity $\left(I_{\mathrm{n}} / I_{\text {total }}\right)$ versus the crystallisation temperature was employed to determine the temperature giving the maximum crystallisation rate and the minimum time required for crystallisation at the optimum crystallisation temperature.

\subsection{Glass-ceramic production and characterisation}

Bulk glass-ceramics samples were prepared following a two-stage crystallisation process. The bulk glass was heated at $5 \mathrm{~K} \mathrm{~min}^{-1}$ up to the optimum nucleation temperature and held for the optimum nucleation time. The nucleated glass was then heated at $5 \mathrm{~K} \mathrm{~min}^{-1}$ up to optimum crystallisation temperature and held for the optimum crystallisation time.

Scanning electron microscopy (SEM) of polished and etched samples (2\% HF for $1 \mathrm{~min}$ ) was used to examine the microstructure of the glass-ceramics produced by various heat treatments. The density of the glass and glass-ceramics was determined by Archimedes' method.

The thermal and mechanical properties of the glass and glass-ceramics have been assessed. Dilatometric measurements were performed in a Netzsch dilatometer between room temperature and $950^{\circ} \mathrm{C}$ on bars $\left(25 \times 5 \times 5 \mathrm{~mm}^{3}\right)$ in order to determine the average coefficient of thermal expansion over the experimental temperature range. Vickers indentation was used to characterise the hardness $\left(H_{v}\right)$ using loads of $300 \mathrm{~g}$. In addition the fracture toughness, $K_{I C}$, was estimated from the length of the cracks arising at the corners of the Vickers indent using the equation [10].

$$
\mathrm{K}_{\mathrm{IC}}=0.048\left(\frac{\mathrm{c}}{\mathrm{a}}\right)^{-1.32}\left(\frac{\mathrm{E}}{\mathrm{H}_{\mathrm{v}}}\right)^{0.4} \mathrm{H}_{\mathrm{v}} \sqrt{\mathrm{a}}
$$

where $E$ is the Young's modulus, which was determined by means of a resonance frequency technique. 
Erosion tests were carried out using sand carried in a stream of air and impacting on the sample at an angle of $90^{\circ}$. The sand feed rate and average velocity were $210 \mathrm{~g} \mathrm{~min}^{-1}$ and $15 \cdot 1 \mathrm{~m} \mathrm{~s}^{-1}$, respectively. Mass loss from the sample was measured after every $150 \mathrm{~g}$ of sand and then converted into volume loss using the density. Erosion rate was obtained from the slope of the plot of volume loss versus mass of sand. The machinability was assessed by cutting with a hard-metal high speed tool.

\section{Result and Discussion}

Fig. 1 shows that the fly ash-residue mixture (TIRME F+L) has a wide particle size range from about 1 to $700 \mu \mathrm{m}$ with mean particle size $\left(D_{50}\right)$ of $40 \cdot 7 \mu \mathrm{m}$. The results of sieving experiments to give the volume of particles in the ranges $<53,53-100,100-150,150-$ $300,>300 \mu \mathrm{m}$ were in good agreement with the Laser Sizer data.

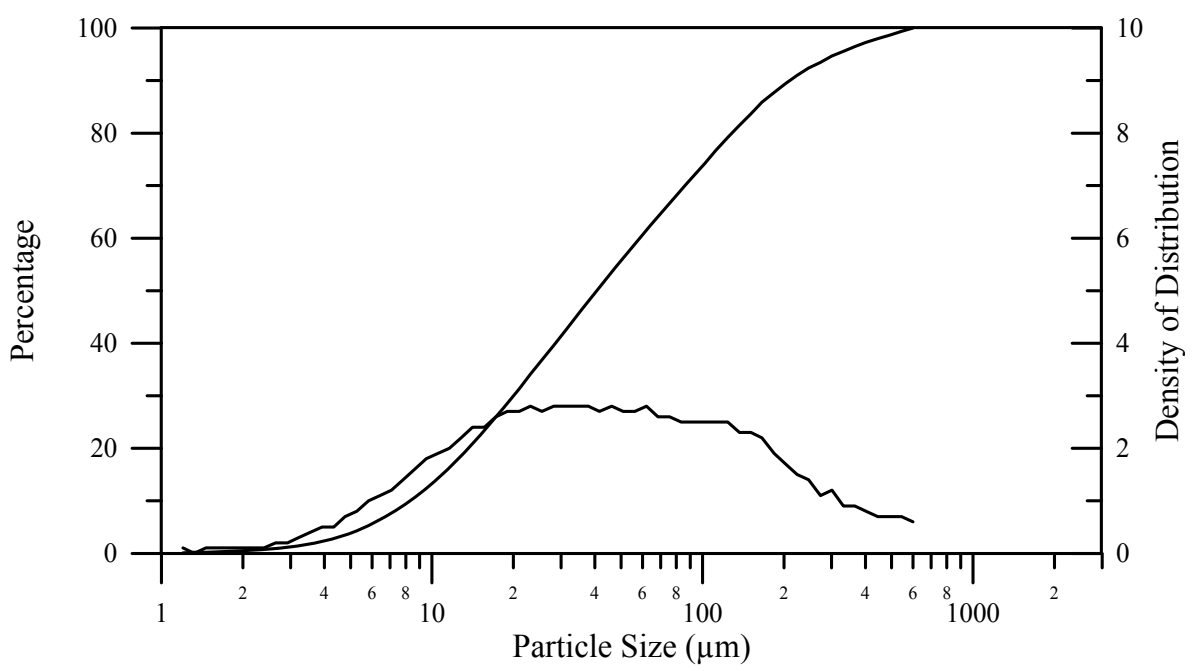

Fig. 1. Density of distribution (-) and particle size distribution, \% (- - -) for fly ash-residue mixture (TIRME F+L).

Table 1 shows the chemical analysis by ICP of TIRME F+L, the major components are $\mathrm{CaO}$, $\mathrm{Na}_{2} \mathrm{O}, \mathrm{SiO}_{2}$ and $\mathrm{Al}_{2} \mathrm{O}_{3}$ and there is significant loss of ignition (LOI), which is probably due to the loss of volatiles associated with the decomposition of the different calcium compounds. The sum of oxides plus LOI is in all cases near to $90 \%$, the remaining $10 \%$ could correspond to elements such as $\mathrm{Cl}$ and $\mathrm{S}$ that cannot be determined by ICP method. It is important to note that species known to be nucleating agents, such as $\mathrm{TiO}_{2}, \mathrm{P}_{2} \mathrm{O}_{5}$, and $\mathrm{Fe}_{2} \mathrm{O}_{3}$, are present in reasonable amounts. The chemical composition of the Spanish waste glass used to adjust the batch composition is also shown in Table 1. 
Table 1. Chemical analysis (wt\%) of TIRME F+L fly ash and Spanish waste glass as determined by ICP method

\begin{tabular}{lcc}
\hline & TIRME (F+L) & Spanish waste glass \\
\hline $\mathbf{C a O}$ & 44.0 & 10.89 \\
$\mathrm{SiO}_{2}$ & 5.5 & 72.47 \\
$\mathbf{A l}_{2} \mathbf{O}_{3}$ & 3.4 & 1.77 \\
$\mathbf{F e}_{2} \mathbf{O}_{3}$ & 0.7 & 1.19 \\
$\mathbf{M g O}$ & 1.5 & 1.30 \\
$\mathbf{N a}_{2} \mathbf{O}$ & 3.7 & 12.38 \\
$\mathbf{K}_{2} \mathbf{O}$ & 2.9 & 0.84 \\
$\mathbf{P}_{2} \mathbf{O}_{5}$ & 0.8 & 0.02 \\
$\mathbf{T i O}_{2}$ & 0.5 & 0.08 \\
$\mathbf{Z n O}$ & 0.65 & 0.01 \\
$\mathbf{L O I}$ & 29.3 & ---- \\
\hline
\end{tabular}

The X-ray diffractogram for TIRME $\mathrm{F}+\mathrm{L}$ is given in Fig. 2. $\mathrm{Ca}(\mathrm{OH})_{2}$ is the major phase but $\gamma$ $\mathrm{CaSO}_{4}, \mathrm{CaCl}_{2} \cdot \mathrm{Ca}(\mathrm{OH})_{2} \cdot \mathrm{H}_{2} \mathrm{O}$ and $\mathrm{CaCl}_{2}$ are also present. Fig. 2 also shows the differences in the proportions of the phases present in the five particle size ranges obtained by sieving. It can be seen that there is a decrease of the major phase $\mathrm{Ca}(\mathrm{OH})_{2}$ and the phases $\mathrm{CaCl}_{2} \cdot \mathrm{Ca}(\mathrm{OH})_{2} \cdot \mathrm{H}_{2} \mathrm{O}$ and $\gamma-\mathrm{CaSO}_{4}$, as the particle sizes increase. In contrast, the $\mathrm{CaCl}_{2}$ percentage increases with increasing particle size. Some fractions are enriched in $\mathrm{SiO}_{2}$ ( $<53 \mu \mathrm{m}$ fraction) and quartz (53-100 $\mu \mathrm{m}$ fraction); these phases could be not detected in the unsieved, as-received mixture.

Table 2 demonstrates that the optimum composition to maximise use of the raw material, while producing a melt with an acceptable viscosity as well as forming a relatively stable glass, is $65 \mathrm{wt} \%$ TIRME F+L $+35 \mathrm{wt} \%$ glass waste (designated TIR65). Greater proportions of raw material resulted in either unstable glasses that crystallised on cooling or batches that were not completely molten at $1500^{\circ} \mathrm{C}$. The process schedule described in Section 2.1 produced homogeneous, transparent, green glass from TIR65; XRD analysis confirmed its glassy nature. 


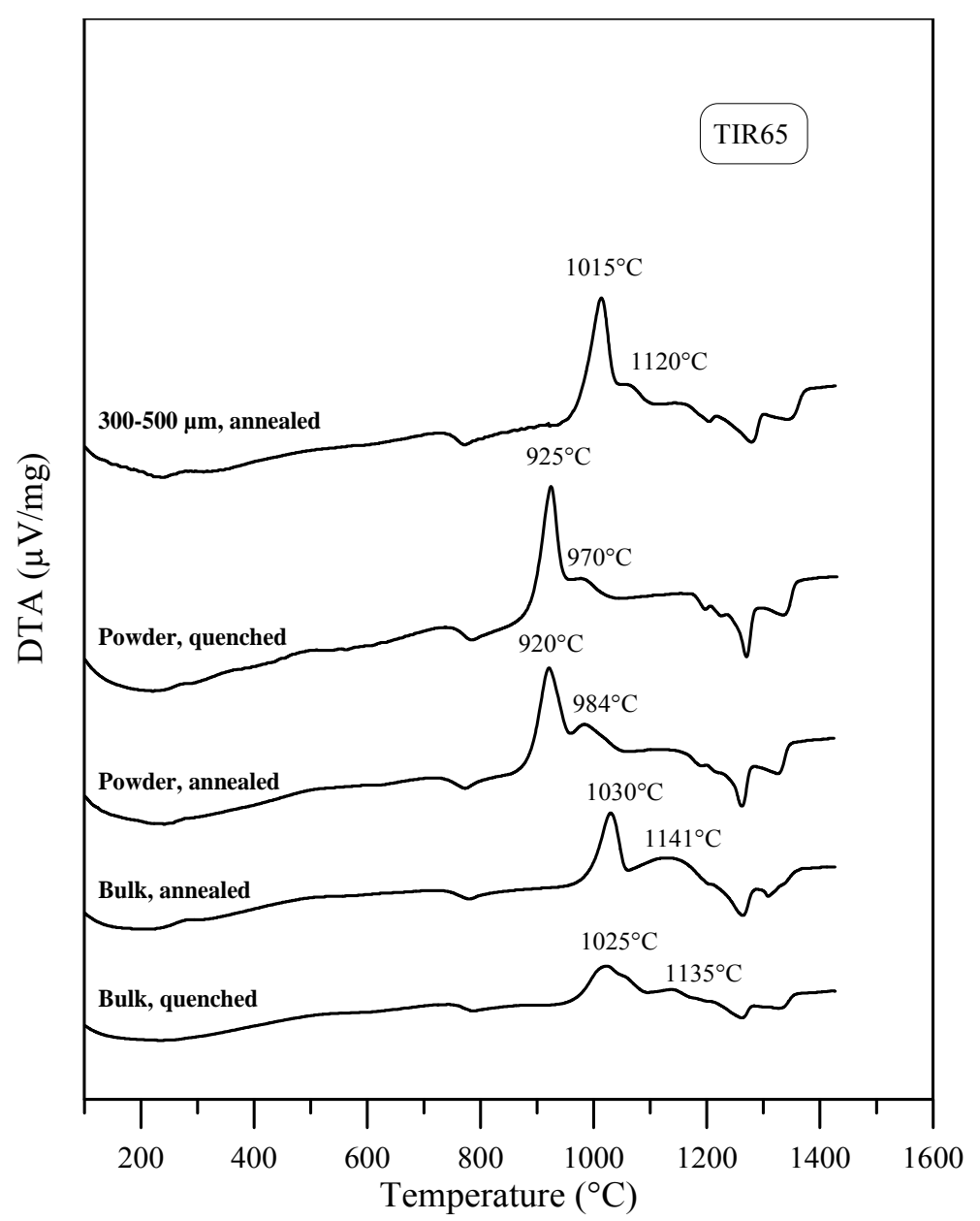

Fig. 2. X-ray diffractogram for as-received TIRME F+L mixture and for the different particle size fractions.

Table 2. Melting and casting observations from different mixtures TIRME F+L and Spanish glass waste and TIRME $(\mathrm{F}+\mathrm{L})$

\begin{tabular}{ccl}
\hline $\begin{array}{c}\text { TIRME } \\
\text { F+L } \\
\text { (wt \%) }\end{array}$ & $\begin{array}{c}\text { GLASS } \\
\text { WASTE } \\
\text { (wt \%) }\end{array}$ & \\
\hline 50 & 50 & Molten at $1500^{\circ} \mathrm{C}$ with acceptable viscosity. Glass formed \\
60 & 40 & Molten at $1500^{\circ} \mathrm{C}$ with acceptable viscosity. Glass formed \\
65 & 35 & Molten at $1500^{\circ} \mathrm{C}$ with acceptable viscosity. Glass formed ( TIR65) \\
68 & 32 & Molten at $1500^{\circ} \mathrm{C}$ with acceptable viscosity. Crystal growth during cooling \\
70 & 30 & Molten at $1500^{\circ} \mathrm{C}$ but high viscosity. Does not pour \\
$>70$ & $<30$ & Not molten at $1500^{\circ} \mathrm{C}$ \\
\hline
\end{tabular}


The DTA curves for powder and bulk (annealed and quenches) samples from TIR65 glass show a glass transition at $750^{\circ} \mathrm{C}$, followed by two exothermic crystallisation peaks and finally an endothermic reaction indicating formation of a liquid phase (Fig. 3). The differences in the crystallisation temperatures for annealed and quenched samples is typically only $5 \mathrm{~K}$ and for all practical purposes may be considered negligible, thus the crystallisation of TIR65 glass does not depend on the rate of cooling of the melt. In contrast the crystallisation temperatures are lower for the fine $(<100 \mu \mathrm{m})$ powder sample, e.g. for the first crystallisation peak $\approx 1030^{\circ} \mathrm{C}$ for bulk and $\approx 920^{\circ} \mathrm{C}$ for fine powder sample, and this indicates that surface crystallisation plays a major role in the crystallisation of the fine powder. The peak temperatures shift to higher temperatures the larger the particle size; the temperatures of the peaks of the coarse powder with particles of 300-500 $\mu \mathrm{m}$, which was used in the nucleation test, are 1015 and $1120^{\circ} \mathrm{C}$ for the first and second crystallisation peaks, respectively, and these temperatures are close to those for bulk samples.

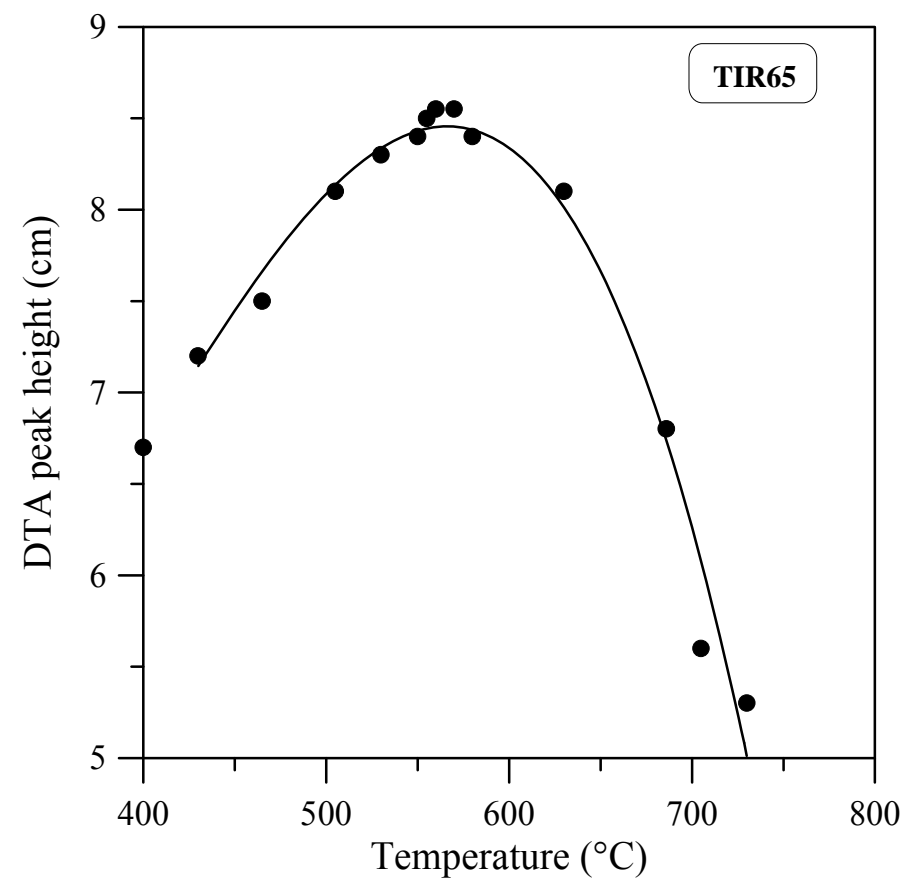

Fig. 3. DTA curves for different TIR65 glass samples.

The plot of crystallisation peak height versus nucleation temperature (Fig. 4) demonstrates that the maximum nucleation rate is about $560^{\circ} \mathrm{C}$ for TIR 65 glass. Fig. 5 is a plot of crystallisation peak height versus nucleation time in samples nucleated at $560^{\circ} \mathrm{C}$; both crystallisation peak heights have been plotted. The first peak curve is unusual in that instead of reaching a plateau after a certain time it exhibits a maximum at around $34 \mathrm{~min}$. The reduction in the effective nuclei number for the first crystallisation peak is attributed to the onset of the second crystallisation reaction. It appears that the latter, at least partly, involves the same nucleii as the 
first crystallisation process, hence the reduction in the number of nucleii available for the first crystallisation peak. It should be noted that the curve for the second crystallisation peak shows the normal characteristics in that a plateau is reached.[11] The time to the plateau is about the same as that to the maximum in the curve for the first crystallisation peak.

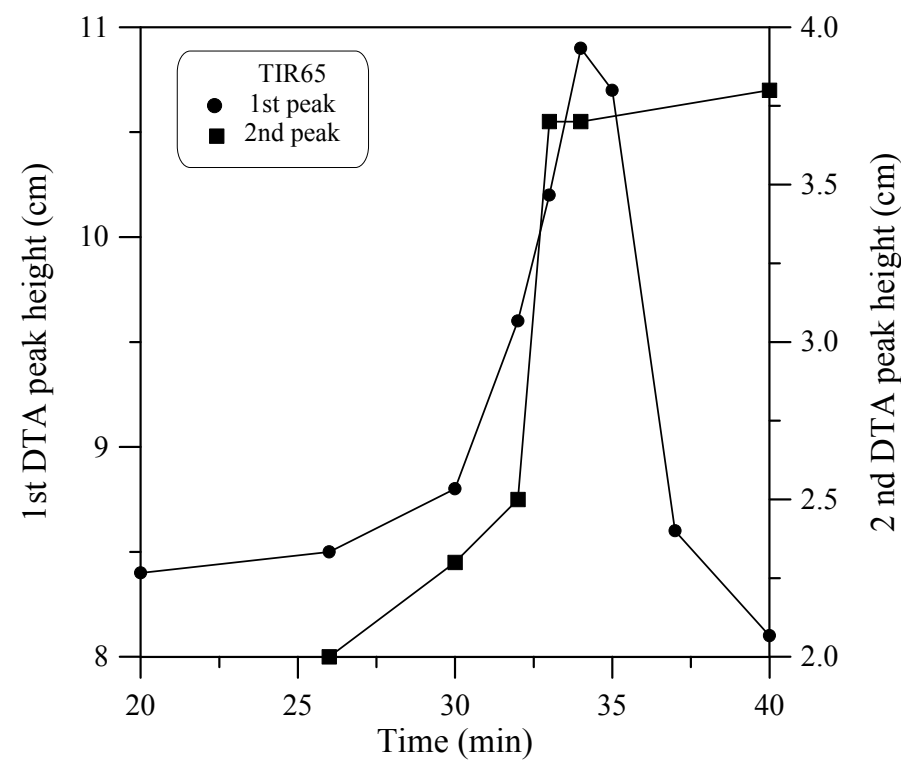

Fig. 4. Identification of the nucleation temperature of $\approx 560^{\circ} \mathrm{C}$ from the plot of the crystallisation peak height versus nucleation temperature for TIR65 glass.

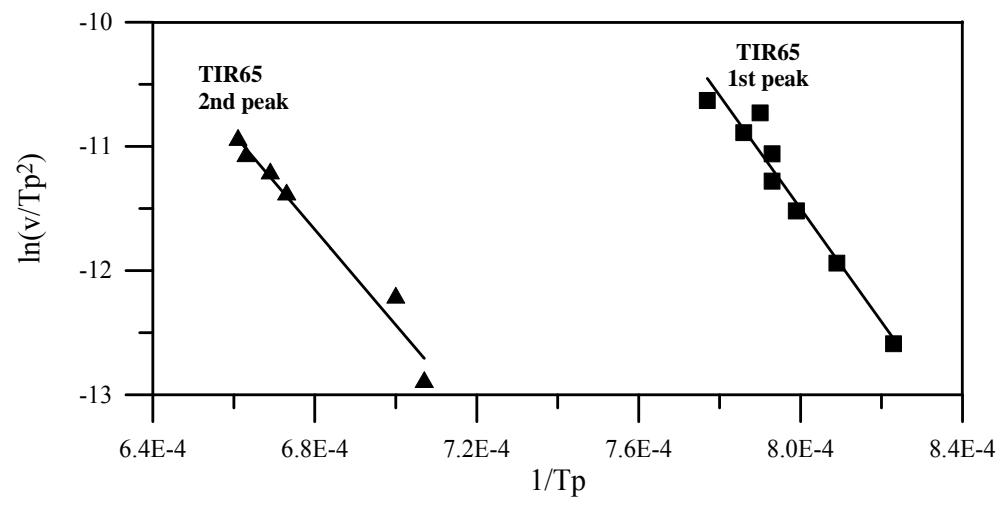

Fig. 5. Plot of crystallisation peak height versus nucleation time at $660^{\circ} \mathrm{C}$ for TIR65 glass.

A linear relationship was obtained between $\ln \left(\varphi / T_{p}^{2}\right)$ versus $1 / T_{p}$ in accordance with the Kissinger equation [Eq. 1] for both crystallisation peaks (Fig. 6). The values of $E$ determined from the slopes of these plots are 379 and $319 \mathrm{~kJ} \mathrm{~mol}^{-1}$ for TIR65 first and second crystallisation peaks. 


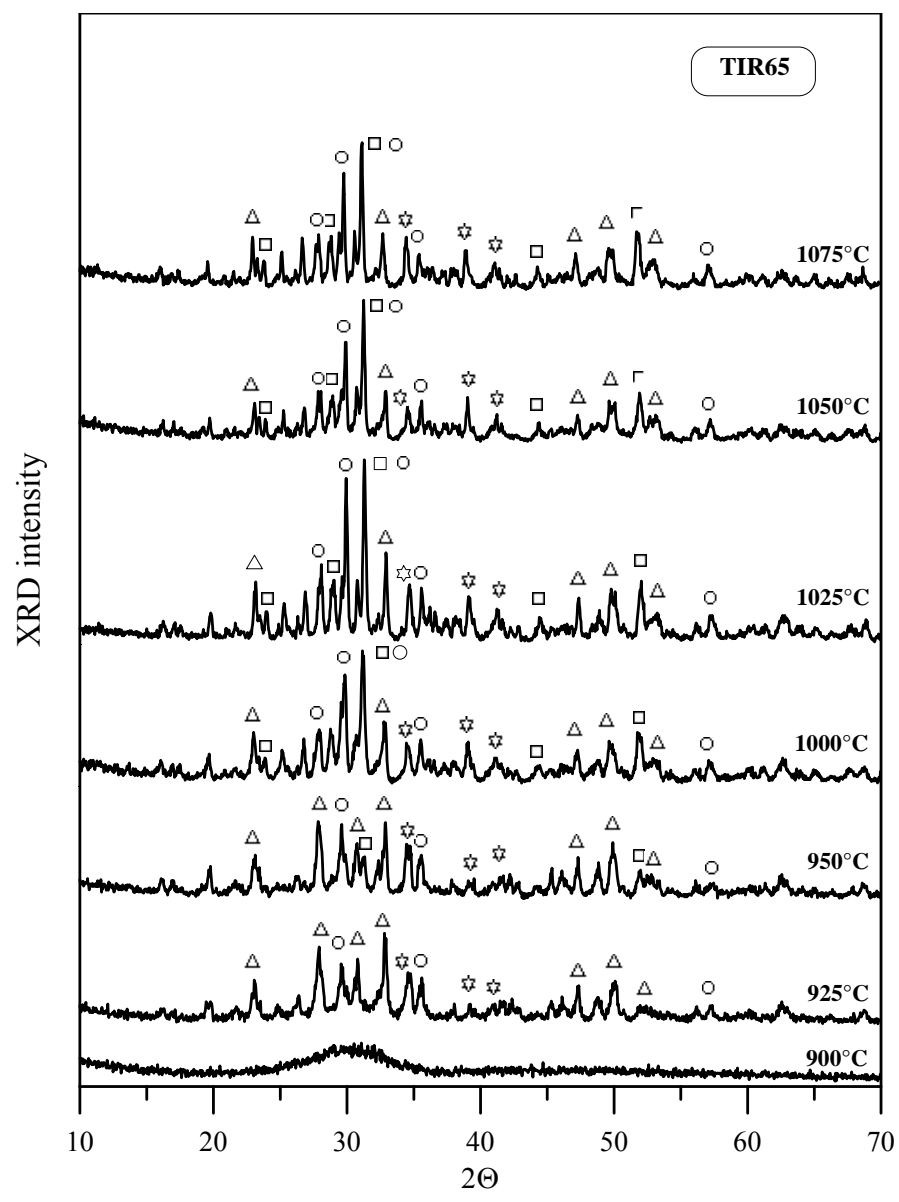

Fig. 6. Determination of the activation energy for crystallisation from the slope of $\ln \left(\varphi / T_{p}^{2}\right)$ versus $1 / T_{p}$ [see Eq. 1].

The Avrami parameters calculated from Eq. 2 are 1.1 and 3.1 for the first and second crystallisation peaks, respectively. A value of $n$ close to 1 denotes surface crystallisation while a value of 3 implies bulk crystallisation.

To investigate the effect of crystallisation temperature on microstructure, bulk glass samples that had received a nucleation treatment of $35 \mathrm{~min}$ at $560^{\circ} \mathrm{C}$ were held at different temperatures in the range $900-1075^{\circ} \mathrm{C}$ for $2 \mathrm{~h}$. The changes resulting from the heat treatments as observed by the naked eye on cross-sections are summarised in Table 3 . The changes start at $925^{\circ} \mathrm{C}$ with the formation of a thin crystallised layer on the glass surface; this is in agreement with the value of 1.1 for the Avrami exponent for the first crystallisation peak. At $950^{\circ} \mathrm{C}$ there is evidence of both surface and bulk crystallisation, the latter being consistent with $n \approx 3$ obtained for the second crystallisation peak. At $1000^{\circ} \mathrm{C}$ the sample is fully crystallised. The fact that bulk nucleation occurs demonstrates that there is sufficient quantity of nucleating agents, e.g. $\mathrm{TiO}_{2}, \mathrm{P}_{2} \mathrm{O}_{5}$ and $\mathrm{Fe}_{2} \mathrm{O}_{3}$, in the raw material. 
Table 3. Effect of heat treatment temperature (heat treatment time $2 \mathrm{~h}$ ) on crystallisation and colour of TIR65

\begin{tabular}{ll}
\hline TEMPERATURE $\left({ }^{\circ} \mathbf{C}\right)$ & \multicolumn{1}{c}{ CRYSTALLISATION } \\
\hline 900 & No evidence of crystallisation. Dark green \\
925 & Surface crystallisation layer. Green \\
950 & Surface + bulk crystallisation. Green \\
1000 & Full crystallisation. Light green \\
1025 & Full crystallisation. Light green \\
1050 & Full crystallisation. Brown \\
1075 & Full crystallisation. Brown \\
\hline
\end{tabular}

Fig. 7 shows the X-ray spectra for TIR65 glass after heat treatment at different temperatures for $2 \mathrm{~h}$. Crystallisation starts at $925^{\circ} \mathrm{C}$ and the crystalline phases identified are clinoenstatite $\left(\mathrm{MgSiO}_{3}\right)$ åkermanite $\left(\mathrm{Ca}_{2} \mathrm{MgSi}_{2} \mathrm{O}_{7}\right)$ and $\gamma$-calcium silicate $\left(\gamma-\mathrm{CaSiO}_{4}\right)$ together with some unidentified peaks. The relative proportions of the phases as a function of temperature were estimated from the ratio $I_{n} / I_{\text {total }}$ where $I_{n}$ is the intensity of a chosen X-ray peak for each phase and $I_{\text {total }}$ is the sum of the intensities of all of the peaks. Due to the overlap of some X-ray peaks for the different crystalline phases it is not possible to use the maximum X-ray intensity peak for each phase. The peaks used for the $I_{n} / I_{\text {total }}$ calculation were $2.98 \AA\left(\mathrm{MgSiO}_{3}\right), 3.07 \AA$ $\left(\mathrm{Ca}_{2} \mathrm{MgSi}_{2} \mathrm{O}_{7}\right), 2 \cdot 72 \AA\left(\gamma-\mathrm{CaSiO}_{4}\right)$ and $2 \cdot 60 \AA$ (unidentified phase). 


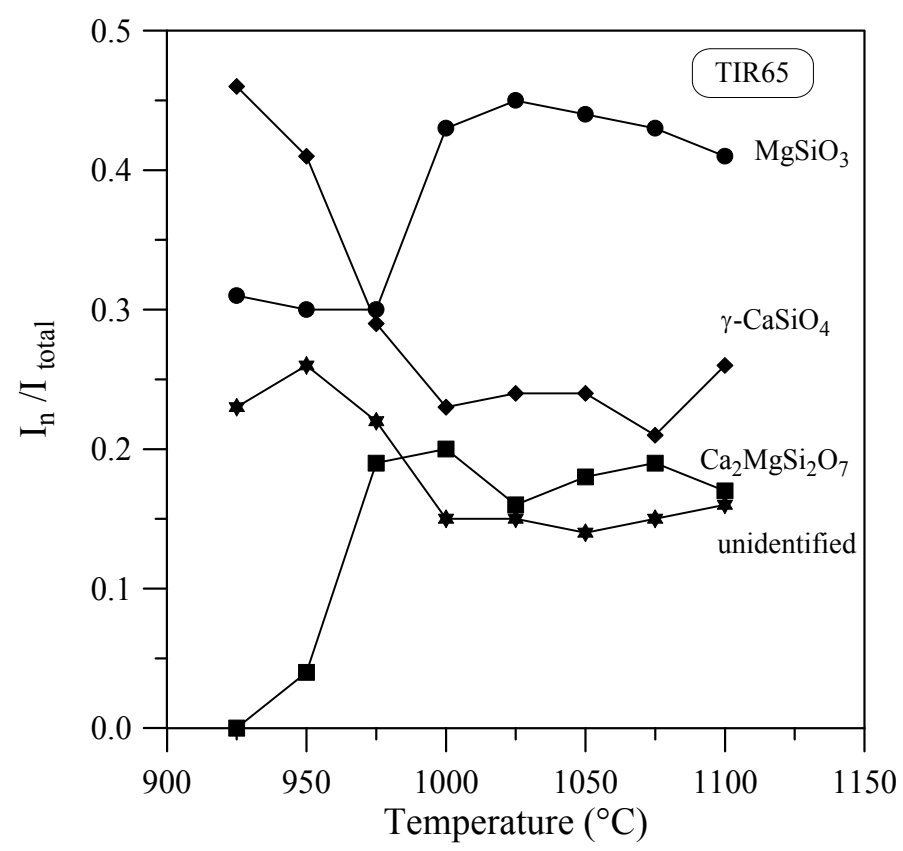

Figure 7. X-ray diffractogram for TIR65 glass after heat treatment for 2 hours at temperatures in the range $900^{\circ} \mathrm{C}$ to $1075^{\circ} \mathrm{C}$ inclusive $\left(\square \mathrm{Ca}_{2} \mathrm{MgSi}_{2} \mathrm{O}_{7} ; \mathrm{O} \mathrm{MgSiO}_{3} ; \Delta \gamma-\mathrm{CaSiO}_{4} ;\right.$ unidentified phase).

The plot of $I_{n} / I_{\text {total }}$ versus crystallisation temperature for TIR 65 glass shows that four crystalline phases are present from early stages of crystallisation (Fig. 8). All the crystalline phases, with the exception of $\mathrm{Ca}_{2} \mathrm{MgSi}_{2} \mathrm{O}_{7}$, are present at the lowest crystallisation temperature of $925^{\circ} \mathrm{C}$ and $\mathrm{Ca}_{2} \mathrm{MgSi}_{2} \mathrm{O}_{7}$ appears by $950^{\circ} \mathrm{C}$. When the temperature increases from 925 to $1000^{\circ} \mathrm{C}$ the relative proportion of $\gamma-\mathrm{CaSiO}_{4}$ and the unidentified phase are reduced and those of $\mathrm{MgSiO}_{3}$ and $\mathrm{Ca}_{2} \mathrm{MgSi}_{2} \mathrm{O}_{7}$ are increased. Above $1000^{\circ} \mathrm{C}$ there are only small changes in the relative proportion of the phases. In order to investigate the effect of crystallisation time, heat treatments were carried out at $1000^{\circ} \mathrm{C}$ for times up to $160 \mathrm{~min}$. The plot of $I_{n} / I_{\text {total }}$ versus crystallisation time of Fig. 9 demonstrates that the proportions of $\gamma-\mathrm{CaSiO}_{4}$, and unidentified phase are reduced whereas the relative proportion of $\mathrm{MgSiO}_{3}$ and $\mathrm{Ca}_{2} \mathrm{MgSi}_{2} \mathrm{O}_{7}$ increases with increasing time up to $2 \mathrm{~h}$. The changes associated with longer ( $>120 \mathrm{~min})$ heat treatments are within experimental error.

The data of Fig. 8 and Fig. 9 indicate that $\mathrm{MgSiO}_{3}$ and $\mathrm{Ca}_{2} \mathrm{MgSi}_{2} \mathrm{O}_{7}$ are the more stable crystalline phases, i.e. the relative proportions of these phases initially increase with time. Also from these figures it may be concluded that a crystallisation treatment at $1000^{\circ} \mathrm{C}$ for $2 \mathrm{~h}$ is the most appropriate treatment to produce a glass-ceramic from TIR65 glass as increasing either the time or temperature of heat treatment has a negligible effect on the degree of crystallisation. 


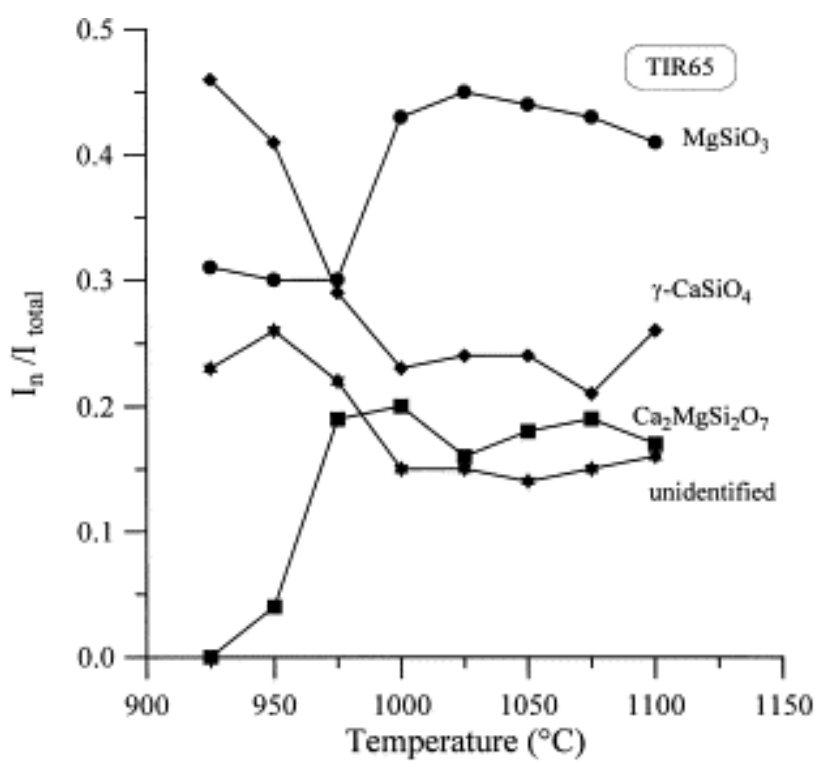

Fig. 8. Plot of $I_{n} / I_{\text {total }}$ versus crystallisation temperature for TIR65 glass (heat treatment time is $2 \mathrm{~h})$

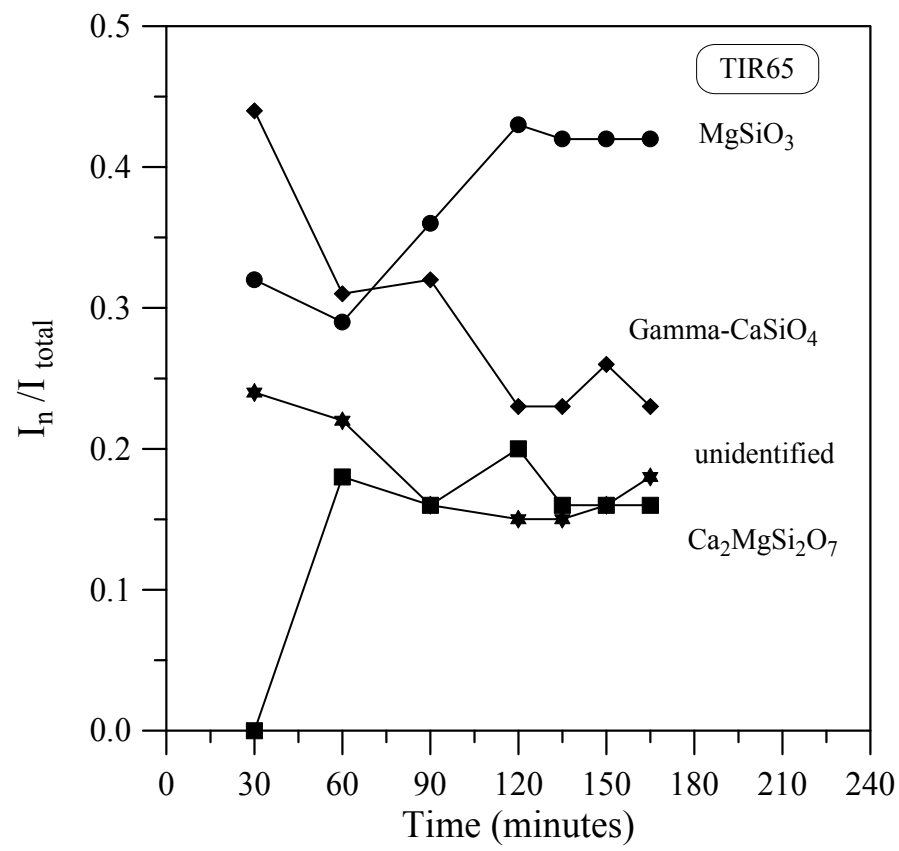

Fig. 9. Plot of $I_{n} / I_{\text {total }}$ versus crystallisation time at $1000^{\circ} \mathrm{C}$ for TIR65 glass.

The microstructures of the heat treated TIR65 samples described in Table 3 are shown in the scanning electron micrographs of Fig. 10 . At $925^{\circ} \mathrm{C} / 2 \mathrm{~h}$ [Fig. 10(a) and Fig. 10(b)] a crystalline layer, consisting of branching leaf-like arms, grows perpendicular to the surface of the sample. Similar surface microstructures can also be seen in the TIR65 samples heat treated at higher temperatures. At $925^{\circ} \mathrm{C} / 2 \mathrm{~h}$ there are no significant differences between the compositions, as 
determined by SEM/EDX, of the crystalline and glassy phases (Table 4). Thus, surface crystallisation does not involve large compositional changes between the crystalline phase and the parent glass. The EDX and XRD analyses indicate that the crystalline phase associated with surface crystallisation is $\gamma-\mathrm{Ca}_{2} \mathrm{SiO}_{4}$.
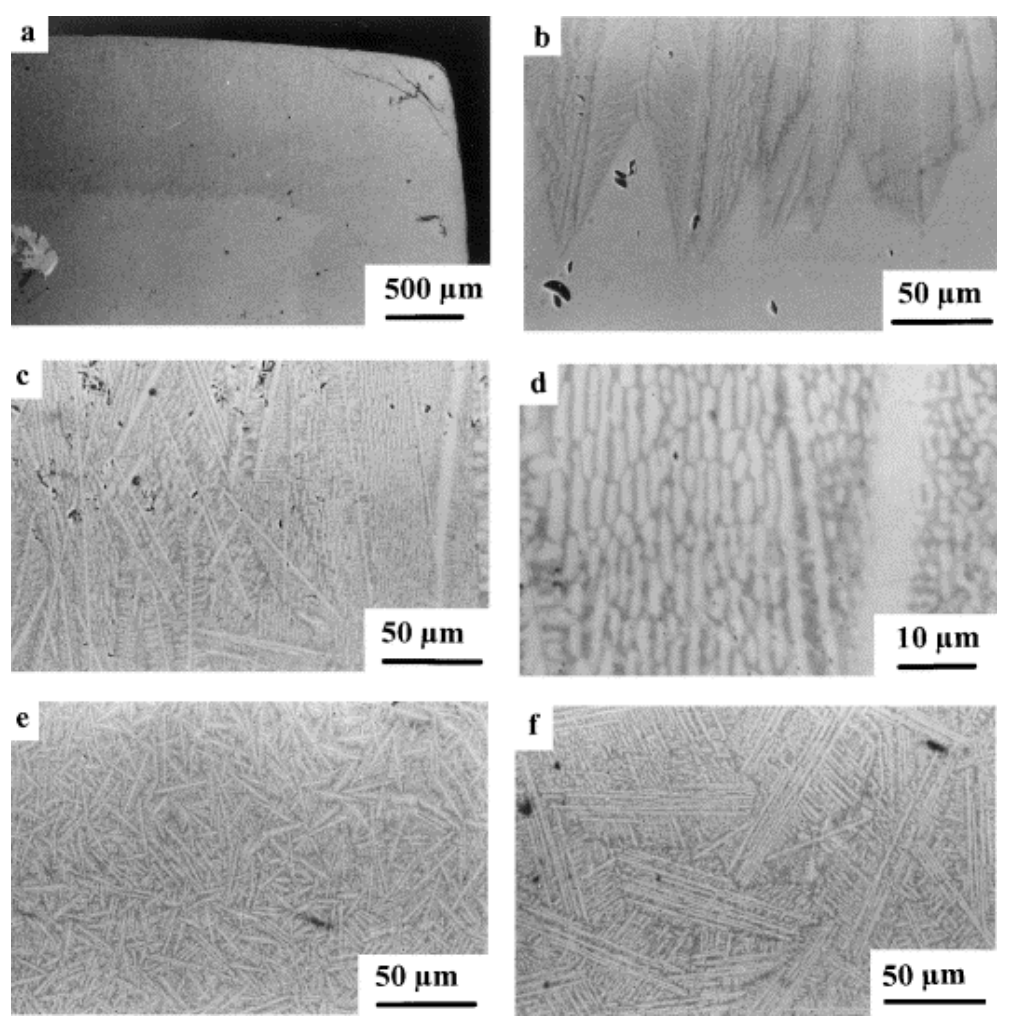

Fig. 10. SEM micrographs of TIR65 samples heat treated at different growth temperatures for $2 \mathrm{~h}$ : (a) and (b) $925^{\circ} \mathrm{C}$, (c) and (d) $950^{\circ} \mathrm{C}$, (e) $1000^{\circ} \mathrm{C}$, (f) $1050^{\circ} \mathrm{C}$.

Table 4. EDX analyses (wt\%) of the glassy and crystallise phases of TIR65 heat treated at different temperatures

\begin{tabular}{clcccccc}
\hline $\begin{array}{c}\text { HEAT } \\
\text { TREATMENT }\end{array}$ & \multicolumn{1}{c}{ PHASE } & $\mathbf{N a}_{2} \mathbf{O}$ & $\mathbf{M g O}$ & $\mathbf{A l}_{2} \mathbf{O}_{3}$ & $\mathbf{S i O}_{2}$ & $\mathbf{C a O}$ & $\mathbf{S i O}_{2} / \mathbf{C a O}$ \\
\hline $925^{\circ} \mathrm{C} / 2 \mathrm{~h}$ & Glassy matrix & 1.14 & 1.82 & 3.95 & 45.84 & 47.25 & 0.97 \\
& Crystalline layer & 1.43 & 1.97 & 5.01 & 44.58 & 47.01 & 0.95 \\
$950^{\circ} \mathrm{C} / 2 \mathrm{~h}$ & Glassy matrix & 3.15 & 4.81 & 7.34 & 45.88 & 38.82 & 1.18 \\
& Fibrillar crystal & 0.07 & 0.90 & 2.16 & 45.11 & 51.76 & 0.87 \\
& Dendritic crystal & 0.35 & 1.27 & 1.85 & 44.62 & 51.91 & 0.86 \\
$1000^{\circ} \mathrm{C} / 2 \mathrm{~h}$ & Fibrillar crystal & 0.08 & 0.77 & 0.85 & 43.51 & 54.79 & 0.79 \\
& Dendritic crystal & 0.14 & 0.48 & 1.28 & 42.95 & 55.15 & 0.77 \\
\hline
\end{tabular}

When TIR65 glass is heat treated at $950^{\circ} \mathrm{C} / 2 \mathrm{~h}$, surface and bulk crystallisation take place simultaneously. The microstructure of the interior where bulk crystallisation occurs is 
composed of fibre-like crystals, whose width is in the range $2-7 \mu \mathrm{m}$ and whose length is variable up to about $200 \mu \mathrm{m}$ [Fig. 10(c) and Fig. 10(d)]. In some areas there is a well defined dendritic structure. EDX analyses collected in spots on fibrillar crystals, dendritic crystals and the surrounding glassy matrix (Table 4) show that bulk crystallisation involves large compositional changes. At $950^{\circ} \mathrm{C} / 2 \mathrm{~h}$ the glassy matrix is enriched in $\mathrm{Na}_{2} \mathrm{O}, \mathrm{MgO}$ and $\mathrm{Al}_{2} \mathrm{O}_{3}$ with respect to the crystalline phase whereas the crystalline phase is enriched in $\mathrm{CaO}$. The $\mathrm{SiO}_{2}$ content is similar in the residual glass and in the crystalline phases, thus the compositional changes produced when bulk crystallisation takes place affect the $\mathrm{SiO}_{2} / \mathrm{CaO}$ ratio; the $\mathrm{SiO}_{2} / \mathrm{CaO}$ ratio in the crystalline phase decreases from 0.95 to approximately 0.87 when the temperature of the thermal treatment increases from 925 to $950^{\circ} \mathrm{C}$ whereas in the glassy matrix the ratio increases from 0.97 to 1.18 over the same interval of temperature. $\mathrm{Th} \mathrm{SiO}_{2} / \mathrm{CaO}$ ratio is approximately the same for fibrillar and dendritic crystals ( $0 \cdot 87$ and $0 \cdot 86$, respectively), the $\mathrm{Na}_{2} \mathrm{O}, \mathrm{MgO}$ and $\mathrm{Al}_{2} \mathrm{O}_{3}$ contents being the major difference between the two types of crystals; the fibrillar crystals are enriched in $\mathrm{Al}_{2} \mathrm{O}_{3}$ while the $\mathrm{Na}_{2} \mathrm{O}$ and $\mathrm{MgO}$ content is greater in dendritic crystals. In spite of XRD analyses identifying $\mathrm{MgSiO}_{3}$, as one of the crystalline phases formed on heat treatment, the EDX results do not confirm the presence of this calciumfree phase. It is possible that the phase identified as $\mathrm{MgSiO}_{3}$ by XRD is not 'pure $\mathrm{MgSiO}_{3}$ ' but a pyroxenic phase, such as augite $\left(\mathrm{CaMg}\left(\mathrm{SiO}_{3}\right)_{2}+(\mathrm{Mg}, \mathrm{Fe})(\mathrm{Al}, \mathrm{Fe})_{2} \mathrm{SiO}_{3}\right)$, which incorporates $\mathrm{Ca}, \mathrm{Mg}$ and $\mathrm{Al}$ in its composition.

At $1000^{\circ} \mathrm{C} / 2 \mathrm{~h}$ the sample is fully crystallized with the main crystal morphologies being fibrelike and dendritic [Fig. 10(e)]. Comparison of the microstructures shown in Fig. 10(e) and Fig. 10 (c) indicates changes in the number and length of the fibrillar crystals as the crystallisation temperature increases from 950 to $1000^{\circ} \mathrm{C}$. At $1000^{\circ} \mathrm{C}$ there are more crystals but with an average length of only $25 \mu \mathrm{m}$, which is smaller than that corresponding to treatment at $950^{\circ} \mathrm{C}$. The microstructure of TIR 65 heat treated at temperatures greater than $1000^{\circ} \mathrm{C}$ is similar to that at $1000^{\circ} \mathrm{C}$ but the fibrillar crystallisation is predominant and the average length is $200 \mu \mathrm{m}$ [Fig. $10(\mathrm{f})]$.

The physical and mechanical properties of TIR65 glass and glass-ceramic are presented in Table 5. The mechanical properties, including erosion resistance, of the glass-ceramic are better than those of the parent glass and are comparable with those of the cast Silceram glassceramics, $[12,13,14]$ Overall the properties are acceptable for applications such as tiles for the building industry. Both the glass and the glass-ceramic performed well in the cutting test with hard-metal high-speed tools. 
Table 5. Physical and mechanical properties of TIR65 glass and glass-ceramic

\begin{tabular}{lcc}
\hline \multicolumn{1}{c}{ PROPERTY } & GLASS & $\begin{array}{c}\text { GLASS-CERAMIC } \\
\mathbf{1 0 0 0}^{\circ} \mathbf{C} / \mathbf{2} \text { hours }\end{array}$ \\
\hline Density $\left(\mathrm{Mg} / \mathrm{m}^{3}\right)$ & 2.96 & 2.95 \\
Hardness $(\mathrm{GPa})$ & 5.5 & 5.9 \\
Young's modulus $(\mathrm{GPa})$ & 121.5 & 134.4 \\
Thermal expansion coef. $\left(10^{-6}{ }^{\circ} \mathrm{C}^{-1}\right)$ & 10 & 9 \\
Fracture toughness, $\mathrm{K}_{\mathrm{IC}}\left(\mathrm{MPa} \mathrm{m}^{1 / 2}\right)$ & 1.1 & 1.5 \\
Erosion coefficient $\left(10^{-5} \mathrm{~cm}^{3} / \mathrm{g}\right)$ & 8.65 & 1.63 \\
Machinability & $\mathrm{Good}$ & $\mathrm{Good}$ \\
\hline
\end{tabular}

\section{Conclusions}

The possibility of fabricating vitreous and glass-ceramic materials from solids residues from domiciliary waste incineration was shown. The major components of the solid residue (TIRME $\mathrm{F}+\mathrm{L}$ ) were $\mathrm{CaO}, \mathrm{SiO}_{2}$ and $\mathrm{Al}_{2} \mathrm{O}_{3}$ but nucleating agents, such as $\mathrm{TiO}_{2}, \mathrm{P}_{2} \mathrm{O}_{5}$, and $\mathrm{Fe}_{2} \mathrm{O}_{3}$ were also present in reasonable amounts. The optimum composition to maximise the use of fly ashes from urban incinerator as raw material and to produce a relatively stable glass with suitable viscosity proved to be $65 \mathrm{wt} \%$ TIRME $\mathrm{F}+\mathrm{L}$ plus $35 \mathrm{wt} \%$ glass cullet (designated TIR65).

DTA scans for TIR65 glass exhibited two exothermic crystallisation peaks. The crystallisation behaviour did not depend on the cooling process whereas the crystallisation temperature shifted to higher temperatures the greater the particle size (from $920^{\circ} \mathrm{C}$ for powder samples to $1030^{\circ} \mathrm{C}$ for bulk samples). This behaviour suggested that surface crystallisation was playing a major role in the crystallisation of the fine powder. The Avrami parameter $n$ was $1 \cdot 1$ and $3 \cdot 1$ for the first and second crystallisation peaks, respectively. These values indicated that both surface (first peak) and bulk (second peak) crystallisation processes were operative. The activation energy $E$ was 379 and $319 \mathrm{~kJ} \mathrm{~mol}^{-1}$ for the first and second peak respectively.

The optimum nucleation temperature and time for TIR65 were determined as $560^{\circ} \mathrm{C}$ and 35 min. Crystal growth commenced at $925^{\circ} \mathrm{C}$ but the most appropriate crystallisation treatment was $1000^{\circ} \mathrm{C}$ for $2 \mathrm{~h}$.

The crystalline phases identified by X-ray diffraction were clinoenstatite $\left(\mathrm{MgSiO}_{3}\right)$, akermanite $\left(\mathrm{Ca}_{2} \mathrm{MgSiO}_{7}\right)$ and gamma-calcium silicate $\left(\gamma-\mathrm{CaSiO}_{4}\right)$; there was also a small amount of an unidentified phase. The proportions of $\mathrm{MgSiO}_{3}$ and $\mathrm{Ca}_{2} \mathrm{MgSi}_{2} \mathrm{O}_{7}$ increased with increasing heat treatment time and temperature. There is some evidence from $\mathrm{EDX}$ that $\mathrm{MgSiO}_{3}$ may not be 
present but instead a piroxenic phase which incorporates $\mathrm{Ca}, \mathrm{Mg}$ and $\mathrm{Al}$ in its composition. The crystals in the bulk of the glass-ceramic had fibre-like and dendritic morphologies.

The mechanical properties of the glass-ceramics were better than those of the parent glass, e.g. fracture toughness was 1.5 and $1.1 \mathrm{MPa} \mathrm{m}^{1 / 2}$, respectively.

\section{Acknowledgements}

One of the authors (MRP) is greatly indebted to the Commission of the European Communities for a Visiting Fellowship (contract number ERBFMBICT 961608 under Marie Curie Programme). The scientific assistance of Dr A. R. Boccaccini and Mr R. Sweeney are appreciated.

\section{References}

1. Montejo, C., Treatment of DSW. Medio Ambiente, sept/oct (1996) 63-65.

2. Manual of Renewable Energies. Vol.4, Incineration of DSW, Instituto para la Diversificación y Ahorro de la Energía, Madrid, 1996.

3. Strnad, Z., Glass-Ceramic Materials. Elsevier Science Publisher, Amsterdam, 1986.

4. Romero, M. \& Rincón J.Ma., Preparation and properties of high iron oxide content glasses obtained from industrial wastes. J.Eur.Ceram.Soc., 18 (1998) 153-160

5. Boccaccini, A.R., Bucker, J. \& Bossert, J., Glass and glass-ceramics from coal fly-ash and waste glass. Tile \& Brick, 12 (1996) 6, 515-518.

6. Barbieri, L., Manfredini, T., Queralt, I., Rincón, J.Ma. \& Romero, M., Vitrification of fly ash from thermal power station, Glass technology, 38 (1997) 5, 165-170.

7. Rawlings, R.D., Production and Properties of Silceram Glass-Ceramic, in Glass-Ceramic Materials: Fundamentals and Applications. Mucchi Editore, Modena, 1997

8. Boccaccini, A.R., Köpf, M. \& Stumpfe, W., Glass-Ceramics from filter dust from waste incinerators. Ceramics International (1995))

9. Kissinger, H.E., Variation of peak temperature with heating rate in differential thermal analysis. J.Res.Natl.Stand. (US), 57 (1956) 4, 217-221. 
10.Evans, A.G. \& Wilshaw, T.R., Quasi-Staic Solid Particle Damage in Brittle Solids - 1. Observations, Analysis and Implications Acta Metall., vol.24, (1976) 939-956.

11.Rincón, J.M., Principles of nucleation and controlled crystallization of glasses. PolymPlast.technol.Eng., 31 /1992) 3-4, 309-357.

12.Carter, S., Rawlings, R.D. Rogers, P.S., Erosion and Microstructural Relationships of GlassCeramics, British Ceramic Proceedings 43, edited by B.C.H.Steele and D.P.Thompson, Institute of Ceramics, London (1988) 13-27.

13. Ponton, C.B., Rawlings R.D. \& Rogers, P.S., Mechanical Properties of Silceram GlassCeramics, Proceedings 37 'Special Ceramics 8’ Institute of Ceramics, London, (1986) 229-234. 14. Carter, S., Ponton, C.B., Rawlings, R.D. \& Rogers, P.S., Microstructure, Chemistry, Elastic Properties and Internal Friction of Silceram Glass-Ceramics, J.Mat.Sci. 23 (1988) 2622-2630. 